\title{
Economia da Defesa: Notas para uma Pesquisa Integrada
}

\section{Defense Economics: Notes for an Integrated Research}

\author{
Gustavo Inácio de Moraes ${ }^{\mathrm{a}}$ \\ Cássia Heloísa Ternus ${ }^{b}$ \\ Guilherme Penha Pinto ${ }^{\circ}$
}

\begin{abstract}
Resumo: O presente artigo tem como objetivo delinear as opções de uma agenda de pesquisa em economia da defesa. A importância do setor pode ser constatada pela geração de empregos, impostos e renda, além da oferta de um bem público essencial, qual seja a proteção contra potenciais ameaças aos recursos e às atividades desenvolvidas nos contextos social e econômico brasileiros. O artigo, portanto, trabalha as articulações possíveis de pesquisa no cenário prospectivo de um país que supera os dilemas sociais e econômicos dos anos de intervenção militar na política nacional e reconhece a importância e necessidade da atividade de defesa nacional à luz do seu potencial de reprodução na sociedade. Sobretudo, destaca-se que não somente é possível articular uma pesquisa microeconômica, estudando os setores, mas também uma pesquisa macroeconômica, ambas fundamentais, convergindo para o cumprimento das funções das atividades de defesa.
\end{abstract}

Palavras-chave: Economia da defesa. Política pública. Bens públicos. Economia brasileira.

\begin{abstract}
This paper aims to summary the options of a research agenda in defense economics. The importance of the sector can be seen by the generation of jobs, taxes and income, as well as the provision of an essential public good, protection against potential threats to resources and activities developed in the context of society and the national economy. This paper, therefore, works the possible articulations of research in the context of a country that overcomes the trauma of years of military intervention in national politics and recognizes the importance and necessity of the activity, as well as its potential for reproduction in society. Above all, it is not only possible to articulate a microeconomic research, studying the sectors as traditional, but also a macroeconomic research, fundamental for the positioning and fulfillment of the functions of the defense activities.
\end{abstract}

Keywords: Defense economics. Public policy. Public goods. Brazilian economy.

\section{JEL Classification: H4; L52; O20.}

a Pontifícia Universidade Católica do Rio Grande do Sul (PUCRS), Escola de Negócios, Programa de Pós Graduação em Economia. Porto Alegre, Rio Grande do Sul, Brasil.

b Universidade Comunitária da Região de Chapecó (UNOCHAPECÓ), Área de Ciências Sociais Aplicadas, Curso de Ciências Econômicas. Chapecó, Santa Catarina, Brasil.

c Marinha do Brasil, Grupamento de Fuzileiros Navais do Rio Grande. Rio Grande, Rio Grande do Sul, Brasil. 


\section{1 lntrodução}

Desde o fim do regime militar no Brasil, o papel das Forças Armadas no contexto brasileiro tem se resumido ao papel constitucional da garantia de fronteiras e segurança nacional. O artigo $\mathrm{n}^{\circ} 142$ da Constituição Federal (BRASIL, 1988, não paginado) estabelece que compete às Forças Armadas, “[...] sob a autoridade suprema do Presidente da República, e destinam-se à Defesa da Pátria, à garantia dos poderes constitucionais e, por iniciativa de qualquer destes, da lei e da ordem".

Porém, além da tarefa principal da defesa da pátria, nas últimas duas décadas diversas atividades subsidiárias vêm tendo papel relevante, como as ações de garantia da lei e da ordem (GLO), em vista dos grandes eventos organizados pelo país, fiscalização do meio ambiente, fiscalização e normatização de diversas atividades econômicas, as quais impactam tanto o orçamento público, quanto as decisões de alocação dos atores privados. Ou seja, no processo de debate da despesa pública brasileira, na conformação do orçamento anual e plurianual, as tarefas subsidiárias vêm tornando-se protagonistas frente às tarefas primazes elegidas pela nossa Carta Maior.

Especialmente no governo Fernando Henrique Cardoso (FHC), essa institucionalização ganhou novos contornos com a instituição do Ministério da Defesa, em 1999, sendo ocupado até os dias atuais, preponderantemente, por civis, e a eliminação dos ministérios particulares atribuídos a cada uma das forças constituintes do sistema de defesa no Brasil, formatadas como comandos de força, agora com dupla subordinação, ao Ministro de Estado da Defesa e ao Presidente da República. Tal movimento foi iniciado, em 1996, com a Política Defesa Nacional (PDN), com grande apatia política, sendo materializado com a Política Nacional de Defesa (PND), em 2005, e, em seguida, pela Estratégica Nacional de Defesa (END), em 2008. Também, o Liuro Branco de Defesa Nacional, em 2012, dedicou um capítulo exclusivo para a economia da defesa. Em função das novas demandas ambientais, em consonância com o direcionamento para as tarefas subsidiárias, recentemente, em 2016-2017, foi promulgado o livro Defesa e meio ambiente: preparo com sustentabilidade, também chamado de livro verde de defesa. Cabe destacar, por fim, que desde novembro de 2016, a PND, a END e o Liuro Branco de Defesa Nacional estão em processo de atualização no Congresso Nacional.

Todavia, o recente alinhamento geopolítico ao grupo dos Brics, ${ }^{1}$ bem como a descoberta de novas reservas de petróleo em duas das áreas mais frágeis do território brasileiro - a Amazônia e o Oceano Atlântico (Amazônia azul) - criam novos e importantes desafios para a gestão da defesa nacional na primeira década do século XXI, em paralelo com a atividade fim e as diversas funções subsidiarias, nos cenários de atuação já consolidados.

1 Grupo composto por Brasil, Rússia, Índia e China. 
Ademais, nota-se uma necessidade de capacitar novamente o setor de indústrias e serviços de armamentos e sistemas no intuito de promover conteúdos nacionais e intensificar a produção de patentes na área, indo muito além de uma Base Industrial de Defesa (BID) por si, deixando o debate simplório da necessidade de previsão de demanda, por meio do monopsônio, com a atuação principal do Estado brasileiro, enriquecendo a discussão com foco na competitividade e na abertura de mercados externos. Além disso, também, atentando para os diversos setores primários e terciários da economia. A recente aquisição de caças para a aeronáutica brasileira, processo que demorou cerca de 12 anos para uma definição, bem como o projeto do submarino de propulsão nuclear, ambos afetados pelos ciclos econômicos e políticos, atestam a dificuldade representada pela ausência de contínua produção na área, inviabilizando os processos de spin-off ${ }^{2}$ e spin-in ${ }^{3}$ no caso brasileiro, o que possibilitaria diversos transbordamentos na economia, a partir das iniciativas industriais e comerciais, bem como da imprescindível expansão global dos agentes nacionais, com vistas à manutenção de ganhos de escala e escopo, garantindo a produção de itens sensíveis e corroborando a influência global do país pelo soft power. ${ }^{4}$

Entre as nítidas vantagens percebidas para um estimulo à indústria de defesa está a geração de renda e emprego, através de efeitos diretos e indiretos causados pelos diversos transbordamentos das iniciativas públicas e privadas, além da oportunidade de se estudar a atuação econômica das forças, no cumprimento de seu papel constitucional.

Sobretudo, cabe destacar que os novos elementos, relativos ao alinhamento geopolítico e a evolução da matriz energética, são temas que podem ser abordados de forma integrada ao papel das forças armadas no Brasil do século XXI, uma vez que as diversas ações que efetivam esses elementos são influenciadas pelo posicionamento das forças armadas.

Este texto explorará essas questões sob a ótica da necessidade de uma pesquisa abrangente em economia da defesa e terá como objetivo principal demonstrar como uma pesquisa integrada e multidisciplinar pode ser mais produtiva, ao invés da reflexão de temas econômicos, estratégicos, de política interna e da geopolítica, como assuntos díspares.

Para tanto, opta-se pela seguinte estrutura neste artigo: a segunda seção resgata a sucessão de acontecimentos que alinha o Brasil ao bloco Brics, liderado, sobretudo, pela China; a terceira seção expõe os desafios postos pela matriz energética brasileira no contexto de atuação regional; a quarta seção discute pontos e temas de contato com a pesquisa em economia da defesa; a quinta seção discute pontos e temas de contato com a pesquisa em economia da defesa; a sexta seção traça as considerações finais da pesquisa.

2 Transbordamento da área militar para a civil.

3 Transbordamento da área civil para a militar.

4 Poder brando, poder de convencimento ou poder suave, nas relações internacionais. 


\section{Alinhamento Geopolítico}

A política externa brasileira passou por fases distintas a partir da redemocratização. A primeira, constituída pelos governos Sarney e Collor de Mello, resultaram em maior aproximação com os países do Cone Sul, tendo como produto específico a constituição do Mercado Comum do Sul (Mercosul) e o fim do programa nuclear para concepção de armamentos, este tendo continuidade para os projetos para fins da geração de energia, no meio civil, e, no meio militar, na propulsão de meios navais.

Em um segundo momento, já no governo FHC, o Brasil articulou a liderança do Mercosul a partir da estabilização monetária, lograda com o Plano Real em 1994. Em paralelo, nesse instante nasce a ambição brasileira, junto a outros países como Alemanha e Índia, em se tornar um membro permanente do Conselho de Segurança da Organização das Nações Unidas (ONU).

Para Miyamoto (2010), a busca por uma projeção global do Brasil tem por base os predicados possuídos pelo Brasil, uma vez que suas capacidades econômicas, demográficas e de recursos naturais destacam-se no contexto global. Nessa estratégia, o autor destaca as privilegiadas relações diplomáticas que o Brasil possui com os países do hemisfério sul.

Uma terceira fase, que pode ser atribuída ao governo Lula da Silva e Dilma Rousseff, é distinta da anterior, pelas novas constituições e alinhamentos geopolíticos. Favorecido pelo crescimento econômico, pelo preço das commodities e pela expansão do crédito, os países dos Brics tornam-se os principais aliados estratégicos. Nessa nova fase, acordos e estratégias comuns são desenhados com os países dos Brics, além de Turquia, Egito e Nigéria, em uma estratégia denominada Sul-Sul. Essa nova fase da diplomacia brasileira teve, também, movimentos ousados como a aproximação com o Irã e a missão pacificadora no Haiti. O principal foco, mais uma vez, tratou-se da cadeira como membro permanente do Conselho de Segurança supracitado. A eleição do representante brasileiro para a diretoria geral da Organização Mundial de Comércio (OMC) mostrou a utilidade e o alcance da estratégia brasileira contra um candidato apoiado pelos Estados Unidos e a União Europeia (UE).

Silva, Oliveira e Brites (2013) apontam a África Ocidental, em especial, como uma região importante para a projeção da defesa nacional no contexto do Atlântico Sul. Porém, como apontado pelos autores, o estabelecimento de acordos com os países dessa região não apenas está relacionado à questão de defesa, mas também à projeção econômica do Brasil, com transferência, quiçá, de tecnologia e produção bélica, algo que os autores também salientam que já é praticado, por exemplo, pela Empresa Brasileira de Pesquisa Agropecuária (Embrapa). 
Destaca-se, além desses acordos, o programa míssil ar-ar em cooperação com a África do Sul, resultando no A-Darter, um míssil, apoiado pela Financiadora de Estudos e Projetos (Finep), para curto alcance (BRASIL, 2012, p. 50).

Portanto, a partir do alinhamento geopolítico do Brasil nos últimos anos, verifica-se uma preocupação focada no processo de internacionalização da economia, porém vislumbrando fatores e países com vantagem estratégica relativa frente aos atores já consolidados no cenário mundial quanto à implementação do soft power e do hard power, ${ }^{5}$ tais como Estados Unidos e UE. Assim, é relevante verificar como a economia da defesa pode ser explorada nesse diapasão no mundo e, em especial, no Brasil.

\section{Economia da Defesa como Linha Teórica}

A economia da defesa é reconhecida dentro do complexo industrial-militar a partir de trabalhos como os de Hartley e Sandler (1995), Handbook of defesne economics, Hitch e McKean (1960), The economics of defense in the nuclear age, Richardson (1960), Arms and insecurity, e Schelling (1960), The strategy of conflict.

Os principais problemas sobre os quais essas pesquisas se ocupam são a corrida armamentista nos anos 1970. Entretanto, na década seguinte ganham relevância o potencial de pesquisa e desenvolvimento, o comércio de armas e as estratégias de desarmamento.

Para uma caracterização da economia da defesa, há duas definições clássicas, apontadas por Hitch e McKean (1960) e Hartley e Sandler (1995). A primeira define a economia da defesa como:

Segurança nacional, do ponto de vista de um economista, seria dependente de três assuntos: (1) a quantidade de recursos disponibilizados, hoje e no futuro; (2) a proporção de recursos alocados para os propósitos de segurança nacional e (3) a eficiência com que os recursos alocados são utilizados (HITCH; MCKEAN, 1960, p. 4, tradução nossa).

Uma definição alternativa é apontada por Hartley e Sandler (1995, p. 6, tradução nossa): "Economia da Defesa é o estudo da alocação de recursos, fluxo de renda, crescimento econômico e estabilização aplicada a tópicos relacionados à Defesa". Essa última definição não invalida a primeira, sendo complementar, porém generalizando os problemas que são objetos da economia da defesa em um caráter mais macroeconômico. Em complementação, na primeira definição destaca-se o aspecto microeconômico de eficiência no uso dos recursos.

Desse modo, os tópicos cobertos pela economia da defesa ganham maior ou menor relevância conforme a necessidade e o interesse das conjunturas interna-

5 Poder de coerção e convencimento, lançando mão do poder militar. 
cional e nacional. McGuire (1995) apresenta os campos de interesse da economia da defesa em tópicos, aos que se pode relacionar a hierarquia de produtos da defesa apresentadas por Walker, Graham e Harbor (1988) e Schonfield (1993).

Quadro 1 - Temas em economia da defesa e segurança internacional

\begin{tabular}{|c|}
\hline Temas \\
\hline Interações estratégicas, corrida armamentista e controle de armas. \\
\hline Formação de alianças, alocação de recursos e comportamento. \\
\hline Interações macroeconômicas durante a guerra, paz, desarmamento e conversão. \\
\hline Economia de comando versus economia de mercado, como recursos para defesa. \\
\hline Mobilização, recuperação de guerra e reconstituição de forças. \\
\hline Otimização e eficiência na composição e nível da força. \\
\hline Relação capital e trabalho. \\
\hline Prontidão militar, equipamentos estratégicos e política para a indústria de defesa. \\
\hline Análise dos contratos de defesa. \\
\hline Dependência de comércio, controle de exportações e sanções comerciais. \\
\hline Defesa em países em desenvolvimento. \\
\hline Não proliferação nuclear e governança internacional sobre materiais sensíveis. \\
\hline Ameaças não governamentais, terrorismo, drogas, refugiados e conformações étnicas e religiosas. \\
\hline
\end{tabular}

Fonte: McGuire (1995, p. 15).

Quadro 2 - Hierarquia de produtos em economia da defesa

\begin{tabular}{|l|}
\multicolumn{1}{|c|}{ Hierarquia } \\
\hline Estratégias militares e conceitos. \\
\hline Forças integradas e sistemas de informação. \\
\hline Plataforma de armas e sistemas de comunicação. \\
\hline Armas completas e partes componentes de comunicação. \\
\hline Subsistemas. \\
\hline Subequipamentos. \\
\hline Componentes. \\
\hline Materiais.
\end{tabular}

Fonte: Walker, Graham e Harbor (1988) e Schonfield (1993 apud DUNNE, 1995).

A economia da defesa pode se valer de diversos dos métodos típicos da teoria econômica, tais como:

a) teoria dos jogos, com a finalidade de compreender a interação estratégica entre dois contendores ou a forma de como se comportar frente a organizações terroristas ou conflitos civis, entre outras aplicações;

b) a organização industrial, para se compreender a dinâmica do setor de equipamentos e contratos para a defesa nacional em suas interações regionais e de articulação da indústria e se estudar as cadeias produtivas, a vulnerabilidade de equipamentos estratégicos, a linha de suprimentos e fornecedores e o potencial de pesquisa e desenvolvimento; 
c) os métodos matemáticos/analíticos, em nível macroeconômico, envolvendo modelos de comércio internacional, econometria de larga escala, matrizes de insumo-produto e modelos de equilíbrio geral computável. Essas metodologias macroeconômicas permitem apurar encadeamentos econômicos em termos de emprego, renda e inovações, bem como estabelecer efeitos sobre o crescimento econômico, até mesmo comparando-os a outras funções orçamentárias.

No caso de modelos econométricos de larga escala, trabalhos seminais foram desenvolvidos nos Estados Unidos, Inglaterra e Canadá. Os trabalhos, relativamente antigos, foram esvaziados dada a perda de importância do planejamento central na economia. Contudo, são interessantes os desenvolvimentos do Department of Defense, dos Estados Unidos, em 1980, Centre for Studies in Defense Resources Management (1983), do Canadá, e Donne e Smith (1984) sobre o Reino Unido. Donne e Smith (2007) realizam um novo exame para a economia britânica em uma situação de corrida armamentista.

Pieroni, D’Agostino e Lorusso (2008) comprovam a relação de cointegração entre gastos em defesa e juros reais, bem como com o crescimento econômico. De toda forma, também constatam que as reduções dos orçamentos a partir do início dos anos 1990 colaboram para a redução das elasticidades de gastos na economia.

Aplicações econométricas de equilíbrio parcial para países com grande tradição militar na vida nacional são estudos comuns. Maizels e Nissikane (1986) avaliam os determinantes dos gastos em defesa em países em desenvolvimento, constatando que, para além dos fatores óbvios como o enfrentamento de estados rivais e grupos opositores internos, é determinante a participação do Estado na economia. Ou seja, quanto mais presente o Estado na economia, maior o orçamento de defesa.

Tal constatação levanta um questionamento acerca da presença do Estado que leva a gastos militares maiores ou da presença de gastos militares que torna o Estado maior. LaCivita e Frederiksen (1991) Frederiksen e La Civita (1987) constatam uma relação de casualidade entre gastos militares e crescimento econômico para a África do Sul, Colômbia e Venezuela, o oposto, ou seja, o crescimento econômico promovendo mais gastos militares para Síria, Turquia, Equador, Sri Lanka e para o total da amostra de países. Finalmente, economias onde ambos gastos militares e crescimento em sentido bidirecional se causavam para Argentina, Myanmar, Chile, El Salvador, Gana, Irã, Paquistão, Filipinas, Espanha, Tailândia e a amostra agregada de países. Entretanto, para um grupo de quatro países não foi percebida qualquer relação.

Lipow e Antinori (1995) constatam que o aumento dos gastos militares na presença de uma ameaça séria externa é indutor de crescimento econômico, ao passo que o mero incremento nas despesas militares não seria suficiente para fazer com que a economia cresça, para o grupo de nações desenvolvidas. Por sua vez, Brumm (1997) constata uma relação positiva entre gastos em defesa e crescimento da renda per capita devido à garantia de direitos de propriedade e geração de tec- 
nologia. Sobre a relação entre crescimento econômico e gastos com defesa, Aizenman e Glick (2006) concluem que o crescimento cai com níveis mais elevados de gastos militares e que as despesas militares na presença de ameaças aumentam o crescimento. Pieroni (2009) nota que há um declínio no grau de substituição entre gastos militares e consumo privado na economia americana. D`Agostino, Dunne e Pieroni (2011) confirmam, ademais, que os gastos em defesa não prejudicam o crescimento da economia americana.

Em contraposição, Chang, Huang e Yang (2011), para um grupo de 90 países entre 1992 e 2006, não encontram evidências de redução do crescimento econômico a partir do incremento de gastos militares. No entanto, quando a amostra é subdividida em continentes, haveria sugestão de impactos negativos sobre o crescimento econômico em países da Europa, Oriente Médio e Sul da Ásia.

Ao compararem o crescimento econômico e o bem-estar, através de um modelo de crescimento endógeno, Shieh, Lai e Chang (2002) acreditam terem obtido o ponto de máximo na participação do setor de defesa no orçamento público, em termos de crescimento econômico, mas inferior ao nível de maximização do bem-estar. Para os autores, isso seria um indicativo sobre a razão para diversos acordos de desarmamentos falharem.

Em uma nova investigação, envolvendo o período de 1988 a 2006 e 157 países, Albalate, Bel e Elias (2012) avaliam os determinantes de gastos em defesa, destacando que países com sistemas presidencialistas tendem a gastar mais em defesa do que sistemas parlamentares.

Outros estudos envolvendo casos particulares e períodos específicos são os de Landau (1996), Dakurah, Davies e Sampath (2001), Abu-Bader e Abu-Qarn (2003), Drtisakis (2004), Kollias, Manolas e Paleologou (2004) e Wu, Tang e Lin (2010).

Hartley (2007), a respeito do projeto de aquisição dos caças Typhoon para a força aérea britânica, nota que resultados qualitativos sobre as aquisições/orçamento militar são mais comuns do que resultados quantitativos, logo invalidando os instrumentos necessários à avaliação econômica, ou seja, a avaliação de custo de oportunidade típica em orçamentos e avaliações de qualidade do gasto.

A utilização de uma matriz insumo-produto também é uma opção para se compreender os encadeamentos da indústria de defesa numa economia nacional. Em especial, na atualidade não há uma discriminação específica para a indústria de defesa dentro do referencial da matriz insumo-produto, estando concentrada nos ramos industriais diversos, bem como na demanda final da administração pública. A possibilidade de desagregação do setor de defesa na matriz insumo-produto potencializaria, ademais, a utilização de modelos de equilíbrio geral computável (CGE), uma vez que, para avaliação de impactos a partir dessa metodologia, tão somente são necessárias informações acerca das relações interindustriais, providas pela matriz insumo-produto, bem como de elasticidades específicas do setor de 
defesa, como elasticidades de exportação, de substituição entre fatores primários (capital, trabalho e energia notadamente) e de outras necessárias.

Para a avaliação de impactos regionais, a matriz de insumo-produto também é útil, uma vez que multiplicadores de impacto se tornam relevantes, especialmente no contexto regional. Braddon (1995) sugere a adoção das matrizes de insumo-produto para essa finalidade, o que é viável a partir de dados desagregados das indústrias setoriais.

\section{Economia da Defesa Brasileira}

O planejamento, anterior ao século XXI, da indústria das políticas de defesa brasileira nunca se constituiu em bases permanentes. Embora o pensamento militar brasileiro tenha destacado a vulnerabilidade brasileira na produção de materiais básicos, disso resultando o planejamento para a constituição das indústrias de base brasileiras, ${ }^{6}$ a produção de equipamentos militares nacionais teve inconstâncias.

Cabe destacar que, durante a vigência da púbere democracia brasileira, após 1988, acordo exposto na segunda seção deste trabalho, paulatinamente as forças armadas buscaram coadunar-se com os objetivos nacionais, em especial quando se trata das relações internacionais - com as ações de suas forças militares, tanto em âmbito interno, com a atualização do sistema burocrático militar, em especial com a criação do Ministério da Defesa, incrementando o debate na sociedade - bem como do cenário externo, participando de ações sob a égide da ONU, colaborando com o alinhamento geopolítico de cada momento político no cenário nacional.

A primeira iniciativa para análise da dimensão econômica da defesa advém da Escola Superior de Guerra (ESG), criada em 1949, analisando a dimensão militar e econômica como interdependentes. Os atores públicos que contribuíram para o período de auge das alocações em setores relacionados com a defesa, a saber os governos militares, foram egressos dessa linha de pensamento forjada nas cadeiras da ESG, por meio de um Estado que possuía o protagonismo das iniciativas do desenvolvimento nacional, embebidos na visão positivista, ou seja, a tecnocracia brasileira decidiria as ações para o alcance dos objetivos nacionais erigidos naquele momento, qual seja a consolidação do poder nacional por meio da criação de indústrias de base e infraestrutura, com o crescimento do número de órgãos estatais e paraestatais. ${ }^{7}$

Para Conca (1993), a mobilização industrial de defesa no Brasil teve início com o ciclo econômico do açúcar, com a iniciativa de estaleiros na Bahia, fazendo

$6 \quad$ Especialmente as indústrias siderúrgicas e de petróleo.

7 Para maiores detalhes sobre a ação positivista do Estado brasileiro, ver Caldeira (2017). 
uso da expertise portuguesa e da matéria-prima com madeira local. Também, o ciclo o ouro, em torno de 1760, deslocou a indústria naval para a cidade do Rio de Janeiro, sendo a indústria naval influenciada pelos ciclos econômicos da época. Por sua vez, Amarante (2012) avança até meados da Guerra do Golfo.

O primeiro ciclo industrial militar, que se estendeu desde a fundação da Casa do Trem, em 1762, até a Revolução Democrática de 1964, era caracterizado por fábricas pertencentes às forças armadas. No segundo ciclo, que vem se encerrar com a Guerra do Golfo, o incremento da participação civil ensejou o aparecimento de inúmeras empresas nacionais dedicadas à produção de material de defesa (AMARANTE, 2012).

O primeiro ciclo industrial militar vigoroso ocorreu na década 1930, além das iniciativas antes da Proclamação da República, entre elas o Arsenal de Marinha da Corte (AMC) no período colonial, sendo que, após a Proclamação da Independência, em especial no Segundo Reinado, a partir do desenvolvimento industrial privado com recursos excedentes do ciclo cafeeiro, o AMC aliado às ações privadas, em especial o Estaleiro da Ponta D'Areia, atendeu os objetivos nacionais da época, como a consolidação territorial na Amazônia com a Companhia de Navegação do Amazonas e os esforços da Guerra da Cisplatina. ${ }^{8}$

Uma primeira experiência foi a constituição da Indústria de Material Bélico do Brasil (Imbel) em 1975 (MIYAMOTO, 2010). A criação desse núcleo industrial justificava-se pelo momento histórico, com a ditadura militar completando mais de uma década no Brasil, mas também pelas políticas de incentivo à indústria brasileira, no contexto dos Planos Nacionais de Desenvolvimento (I e II PND), em uma decisão de alinhar o desenvolvimento nacional por meio de iniciativas autóctones, ao contrário da tendência global de internacionalização das iniciativas estratégicas de posicionamento competitivo das diversas indústrias.

Em um segundo momento, a discussão do Projeto Calha Norte domina o debate em defesa durante os anos 1980, atendendo à reorientação geopolítica para a Amazônia. Embora a presença do Estado brasileiro já possa ser mais bem sentida durante os projetos de interiorização, simbolizados pela construção de rodovias e pela instalação da zona franca de Manaus, o projeto Calha Norte seria o ápice dessa presença em regiões de fronteira. Nascimento (2006) argumenta que a presença estatal nessas condições implicaria em queda na qualidade de vida da população, sem a postulação de mecanismos democráticos de controle. Essa percepção teria se acentuado com a prioridade concedida ao Sistema de Vigilância da Amazônia (Sivam) e à redução do papel do Calha Norte durante o final dos anos 1990. Em que pese essas preocupações, o projeto Calha Norte tem sua área ampliada abrangendo cerca de 151 municípios em uma faixa territorial equivalente a $25 \%$ da área do território nacional (NASCIMENTO, 2006).

8 Para saber mais sobre as iniciativas privadas, ver Lessa (2004). 
Na Política Nacional de Defesa (BRASIL, 2005) e na Estratégia Nacional de Defesa (BRASIL, 2008), teve-se o reconhecimento para o enfoque em resultados econômicos, especialmente no domínio de tecnologias nacionais para fornecimento de material às forças. Essas políticas estavam alinhadas com os objetivos nacionais, implementados dentro do novo posicionamento do país, nas relações internacionais, após a redemocratização, em 1985, consolidando-se com a reforma econômica do Plano Real a partir de 1994.

A preocupação com o conteúdo nacional pode ser percebida na concorrência dos novos equipamentos da aeronáutica, cujo consórcio vencedor foi aquele que se comprometeu em transferir a maior parcela de conteúdo tecnológico, em que pese a relação custo benefício. Em especial, a ênfase na formação do pessoal técnico é destacada no documento, alinhado a "[...] organizar o regime legal, regulatório e tributário da indústria nacional de material de Defesa [...]” (BRASIL, 2008, p. 34). Esse cenário foi catalisado pelas iniciativas geopolíticas de alinhamento dos governos FHC com a aquisição do aeródromo São Paulo junto à França e incrementada pelo posicionamento do governo Lula na aquisição de aeronaves - com grande apelo de off-set junto a Embraer - e pelo Programa Nuclear da Marinha, com ação efetiva de transferência de tecnologia entre a estatal DCNS e os organismos brasileiros.

Cabe ressaltar que, com a consolidação do contexto do Atlântico Sul com área de interesse estratégico, o aporte tecnológico adquirido pelas iniciativas dos governos na área de relações internacionais contribuiu para uma aproximação junto à África Ocidental, tendo o Brasil como mediador da modernização do material e do pessoal em alguns países africanos.

Nesse sentido, Schmidt (2011) elenca e ressalta a importância do setor espacial brasileiro, que, sem o apoio institucional - de instituições como o Banco Nacional de Desenvolvimento Econômico e Social (BNDES) e o Fundo Nacional de Desenvolvimento Científico e Tecnológico (FNDCT) - seria inviável. Essa experiência, certamente, serve de inspiração para a estruturação da indústria de defesa e seus polos distribuídos no território nacional.

No bojo da transparência e na busca de dirimir custos de transação causados pela falta de informações, o Liuro Branco de Defesa Nacional (BRASIL, 2012), além de elucidar as tarefas das forças armadas e discorrer sobre as potencialidades operativas, dedica capítulos para a transformação da defesa, discorrendo sobre o Programa de Reaparelhamento e a modernização da gestão, bem como dedica um capítulo para a economia da defesa, tratando dos programas orçamentários de defesa e das alocações internacionais e nacionais efetuadas pelo governo brasileiro, iniciativas que contribuíram para o alinhamento estratégico frente aos organismos internacionais, uma vez que as entidades internacionais, como a ONU, vislumbraram no Brasil uma estrutura conceitual alinhada com os diversos atores globais, em especial, os Estados Unidos e a UE, grandes contribuintes daquela entidade internacional. 
No bojo da discussão sobre alocação de recursos orçamentários de defesa, Schmidt e Assis (2013, p. 55) ressaltam a baixa aquisição nacional pelo Ministério da Defesa brasileiro, com apenas $6,2 \%$ de produtos típicos de defesa. A análise econométrica desenvolvida demonstra quais as características microeconômicas que determinariam o sucesso em vendas para o aparato de defesa brasileiro, tais como a presença do perfil exportador, de dedicação à pesquisa e desenvolvimento, assim como a renda média praticada na firma e a sua participação no total da renda do setor.

Ressaltando a importância da articulação da indústria de defesa, corroborando a END, Amarante (2012) destaca os principais atores do setor: universidades, empresas de engenharia, centros de pesquisa e desenvolvimento, empresas privadas e públicas de base industrial e empresas de serviços. Em essência, para o autor, esses atores refletem as denominadas cinco bases de defesa. ${ }^{9}$ Por fim, a indústria de defesa ideal na percepção do autor seria constituída por três pilares que perpassariam as cinco bases: a) a competência técnica; b) a competência industrial; e c) a competência estrutural-administrativa.

Igualmente, não bastasse a necessidade de integração dessas capacidades, Amarante (2012) cita ainda outro aspecto essencial dentro da operação de defesa calcada na distinção entre planejamento de capacitação imediata e planejamento de capacitação mediata e longínqua. No primeiro caso, o planejamento volta-se para tecnologias acessíveis e/ou simples, ao passo que no segundo caso abordam-se tecnologias e meios com maturação lenta que exigem um aperfeiçoamento e operacionalização mais cuidadosa. Assim, uma combinação ótima intergeracional dos objetivos e recursos a serem empregados é necessária nessa perspectiva. Em especial, frente ao alinhamento estratégico demonstrado nos últimos 10 anos de crescimento da atuação no cenário internacional, fato que demanda planejamento de longo prazo para a manutenção da capacidade competitiva do conhecimento, técnicas e produtos de defesa.

As novas configurações tecnológicas talvez acentuem a necessidade de maiores investimentos tecnológicos e ampliem o perfil de pesquisa e desenvolvimento presente na indústria de defesa. Nesse sentido, sabotagens eletrônicas e ataques por sistemas, como a introdução de vírus e outros recursos, tendem a se tornar cada vez mais comum, não apenas na infraestrutura de defesa, mas também na infraestrutura econômica, ampliando as vulnerabilidades (CRUZ JÚNIOR, 2013), já que a projeção global do Brasil, intensificada no governo Lula e alavancada pelas vantagens competitivas, tais como recursos naturais escassos, atraem a atenção dos atores internacionais públicos e privados, a partir de uma ação de política comercial agressiva.

Desse modo, ganha especial relevância a diferença da proporção e do montante investido no Brasil e nos Estados Unidos, bem como o aparato institucio-

9 São elas a científica, tecnológica, infraestrutural, industrial e logística. 
nal. Cruz Júnior (2013) demonstra que, com exceção da China, os países do Brics encontram-se em um estágio inferior aos Estados Unidos no que diz respeito à formatação de uma ampla rede de proteção. Novamente, porém, surge a necessidade de esquemas tributários, bem como leis e regulações adequadas para incentivarem e nortearem as obrigações de longo prazo para a indústria, os serviços e as cadeias de suprimento de gêneros básicos, avaliando as potencialidades e peculiaridades regionais do imenso território brasileiro.

Essas iniciativas devem preceder, ou no mínimo serem concomitantes, à efetivação de uma postura ativa do Estado frente ao concerto das nações, portanto nas relações internacionais, tal como aplicada nos últimos anos. Ou seja, as políticas internas devem estar alinhadas ao posicionamento do país no cenário geopolítico internacional.

Todas as considerações anteriores, contudo, envolvem questões estratégicas e de orientação quanto ao papel do setor de defesa no Brasil. Porém, tal orientação só poderá ser aperfeiçoada com a melhor gestão na alocação e, eventualmente, o acréscimo de recursos públicos e privados.

Matos (2010) ilustra a estabilidade do orçamento de defesa brasileiro em torno de $1,5 \%$ do PIB entre os anos de 2004 e 2009. No perfil da despesa, chama a atenção o fato de que cerca de $80 \%$ das despesas serem destinadas a pessoal e encargos sociais, ao passo que apenas $5 \%$ serem destinadas a investimentos, ademais o pagamento de inativos e pensionistas representa mais de $60 \%$ dos pagamentos realizados ao pessoal ativo. Ou seja, grosso modo, a cada três funcionários ativos, há dois funcionários inativos ou pensionistas. Então, percebe-se que a "função de produção" em defesa do Brasil está demasiado concentrada em pessoal em prejuízo de equipamentos. Por fim, Matos (2010) observa que, dentre os Brics, Rússia, Índia e China possuem dispêndios maiores que o Brasil em proporção ao PIB.

Ao analisar um período assemelhado, 2001 a 2007, Reiss (2008) nota que a redução do orçamento de defesa é uma tendência mundial da qual o Brasil não escapa. No entanto, confirma que há um exagero na proporção de pagamento a pessoal frente ao orçamento nacional de defesa. Ademais, seria necessário, na opinião do autor, um esforço adicional "[...] na integração da operação e administração das três Forças” (REISS, 2008, p. 12, tradução nossa).

Para os próximos anos, necessidades de materiais e equipamentos são estimadas entre $\mathrm{R} \$ 50$ bilhões e $\mathrm{R} \$ 100$ bilhões por Miyamoto (2010), o que atrai a atenção de vários produtores mundiais. Essas aquisições, associadas às exportações de materiais bélicos, sobretudo aeronaves, pelo Brasil tem, de acordo com o autor, avançado a passos largos no sentido de mostrar condições de defender seus interesses e amplificar seu potencial econômico e político.

A esse propósito, Moraes (2010) ressalta a retomada das exportações brasileiras de armas na primeira década do século XXI, após o auge no período entre 1974 
e 1993, fruto da idealização do Imbel e concentrada em equipamentos como carros de combate e mísseis, sendo que na atual fase, contudo, a concentração modifica-se para a venda de aeronaves, em especial do Super Tucano pela Embraer.

É ainda interessante observar que apesar da concentração em pessoal e encargos sociais, o gasto com defesa nacional para o caso brasileiro tem uma relação positiva com o crescimento econômico, de acordo com Rocha e Giuberti (2005). Porém, Aragão, Ciro, Sobral e Melo (2012) encontram resultado que mostra uma elasticidade baixa, porém positiva para gastos com defesa nacional no Brasil entre 1980 e 2010.

A discussão no Brasil sobre os setores ligados à economia da defesa está muito voltada para a Base Industrial de Defesa, a qual apresenta relativamente uma maior organização frente aos setores de serviços e de itens primários, em especial pela Associação Brasileira das Indústrias de Materiais de Defesa e Segurança (Abimde). No próximo seguimento discutem-se alguns pontos do setor.

\section{Posição do Setor no Brasil}

As ações para depreender qual o método, bem como o arcabouço teórico a ser aplicado em uma discussão não devem prescindir da iniciativa voltada para a elucidação do tema no cenário a ser analisado, nesse caso o Brasil. Esse segmento propõe-se a dirimir, mesmo que superficialmente, o vácuo existente na discussão nacional sobre o setor de defesa. O objetivo desta seção é apresentar o panorama em termos de emprego e renda dos principais setores de defesa no Brasil.

A esse respeito, o Brasil já possui, através da Relação Anual de Informações Sociais (Rais), alguns indicadores do mercado de trabalho de atividades produtivas nos subsetores industriais relacionados à defesa e segurança nacionais. No entanto, não se descartam números maiores, já que há uma cadeia de suprimentos de equipamentos civis, como alimentos, roupas, combustíveis e artefatos, para abastecimento do setor de defesa.

O principal subsetor na economia da defesa brasileira é a atuação dos militares da ativa das forças brasileiras. Segundo a Rais (vários anos), são 331.222 trabalhadores ativos na defesa para o ano de 2013, enquanto esse número foi de 201.077, no ano de 2007, no menor momento da série. Em todos os setores aqui listados como pertencentes à indústria de defesa, há 394.988 trabalhadores, ou quase $1 \%$ da força de trabalho formalizada no Brasil, dados que ensejam uma discussão acerca da relação capital e trabalho, em especial quanto à otimização do recurso trabalho na função de produção, pela simples conformação relativa do quantum frente aos demais setores da economia.

O segundo maior subsetor da indústria é o de fabricação de aeronaves, com 20.373 trabalhadores, também um dos poucos setores que teve declínio no número de postos desde 2007. Curiosamente, é apenas acompanhado, nesse declínio, 
do subsetor de manutenção de aeronaves. Como nessa estatística se enquadram também as aeronaves para fins civis, é de se registrar a curiosa relação com a evolução do número de passageiros desde então, em contradição com esse declínio.

Os dados demonstram, ademais, a importância do estímulo ao setor de aviação militar como ação contracíclica à evolução do setor de aviação civil na geração de postos de trabalho. Nesse setor, caracterizado por bens duais que atendem tanto o meio civil quanto o meio militar, a conformação de alianças e a discussão de investimentos não estão presentes no arcabouço teórico brasileiro, fato demonstrado pela recente discussão do posicionamento estratégico da Embraer no mercado internacional, com o assédio de um grande player do mercado global, a Boeing, fator de instabilidade e dúvidas sobre os ganhos de mercado frente ao itens sensíveis da segurança nacional, especialmente no setor de aeronaves militares. Ou seja, o debate vigente é órfão de embasamento autóctone sobre o tema, embebido em conceitos de organização industrial e de interação estratégica.

Tabela 1 - Evolução anual do número de funcionários nos setores ligados à economia da defesa

\begin{tabular}{ccccc}
\hline Ano & Defesa & $\begin{array}{c}\text { Equipamento bélico } \\
\text { pesado, armas e munição }\end{array}$ & Explosivos & $\begin{array}{c}\text { Manutenção } \\
\text { de aeronaves }\end{array}$ \\
\hline 2013 & 331.222 & 6.868 & 8.567 & 6.752 \\
2012 & 256.220 & 6.786 & 8.217 & 7.119 \\
2011 & 272.292 & 7.637 & 7.367 & 6.747 \\
2010 & 255.084 & 7.613 & 7.421 & 6.505 \\
2009 & 263.782 & 8.039 & 6.993 & 6.162 \\
2008 & 246.514 & 6.891 & 7.052 & 5.812 \\
2007 & 201.077 & 6.662 & 6.274 & 6.907 \\
2006 & 214.422 & 5.971 & 6.503 & 7.152 \\
\hline & Fabricação & Construção & Manutenção & Fabricação \\
Ano embarca- & de turbinas \\
\hline 2013 & de aeronaves & de embarcações & ções & 2.705 \\
2012 & 20.373 & 7.930 & 10.571 & 2.613 \\
2011 & 19.085 & 5.799 & 7.085 & 2.741 \\
2010 & 18.937 & 4.671 & 5.093 & 2.563 \\
2009 & 18.758 & 4.211 & 3.650 & 1.530 \\
2008 & 17.447 & 3.894 & 3.316 & 1.874 \\
2007 & 22.647 & 4.052 & 3.514 & 1.594 \\
2006 & 17.491 & 3.575 & 2.209 & 692 \\
\hline
\end{tabular}

Fonte: Elaboração própria a partir de dados da Rais.

Outra característica relevante é o perfil dos trabalhadores da indústria de defesa em função de seus rendimentos. Em cinco dos oito subsetores (equipamento bélico, manutenção de aeronaves, construção de embarcações, manutenção de embarcações e fabricação de turbinas) predominam trabalhadores que recebem 
entre dois e quatro salários mínimos mensais. Em dois subsetores (defesa e explosivos) predominam trabalhadores com rendimentos entre zero e dois salários mínimos mensais. Em apenas um setor predominam os trabalhadores que recebem entre quatro e sete salários mínimos mensais (fabricação de aeronaves). No setor de fabricação de aeronaves, ademais, há quase 10\% dos trabalhadores recebendo mais de 20 salários mínimos mensais, em contraste com a indústria de explosivos, na qual 55,4\% dos trabalhadores estão concentrados na faixa entre zero e dois salários mínimos. Tais dados denotam que os setores, em sua maioria, não abarcam trabalhadores qualificados, portanto o impulso junto aos demais setores da economia, bem como a competitividade podem estar comprometidos, fato que coloca os setores em uma posição de desvantagem nas cadeias produtivas nacionais e internacionais de bens com alto nível de capital humano, quando da competição por esse insumo.

Tabela 2 - Perfil salarial nos setores ligados à economia da defesa (2013)

\begin{tabular}{|c|c|c|c|c|}
\hline $\begin{array}{l}\text { Número de } \\
\text { salários } \\
\text { mínimos }\end{array}$ & Defesa & $\begin{array}{l}\text { Equipamento béli- } \\
\text { co pesado, armas } \\
\text { e munição }\end{array}$ & Explosivos & $\begin{array}{l}\text { Manutenção } \\
\text { de aeronaves }\end{array}$ \\
\hline 0 a 2 & $31,60 \%$ & $17,18 \%$ & $55,40 \%$ & $22,56 \%$ \\
\hline 2 a 4 & $20,39 \%$ & $37,22 \%$ & $29,15 \%$ & $25,09 \%$ \\
\hline 4 a 7 & $21,02 \%$ & $21,02 \%$ & $8,53 \%$ & $23,36 \%$ \\
\hline 7 a 10 & $13,29 \%$ & $8,21 \%$ & $2,94 \%$ & $12,57 \%$ \\
\hline 10 a 20 & $11,98 \%$ & $7,59 \%$ & $2,78 \%$ & $12,81 \%$ \\
\hline Mais de 20 & $1,72 \%$ & $2,04 \%$ & $1,20 \%$ & $3,61 \%$ \\
\hline $\begin{array}{l}\text { Número } \\
\text { de salários } \\
\text { mínimos }\end{array}$ & $\begin{array}{l}\text { Fabricação } \\
\text { de aeronaves }\end{array}$ & $\begin{array}{l}\text { Construção de } \\
\text { embarcações }\end{array}$ & $\begin{array}{l}\text { Manutenção de } \\
\text { embarcações }\end{array}$ & $\begin{array}{l}\text { Fabricação } \\
\text { de turbinas }\end{array}$ \\
\hline 0 a 2 & $4,40 \%$ & $15,70 \%$ & $19,60 \%$ & $11,28 \%$ \\
\hline 2 a 4 & $11,39 \%$ & $37,23 \%$ & $43,87 \%$ & $41,74 \%$ \\
\hline 4 a 7 & $22,47 \%$ & $30,65 \%$ & $22,98 \%$ & $19,78 \%$ \\
\hline 7 a 10 & $22,13 \%$ & $7,47 \%$ & $5,34 \%$ & $12,53 \%$ \\
\hline 10 a 20 & $30,01 \%$ & $6,47 \%$ & $5,13 \%$ & $12,94 \%$ \\
\hline Mais de 20 & $9,60 \%$ & $2,48 \%$ & $3,07 \%$ & $1,74 \%$ \\
\hline
\end{tabular}

Fonte: Elaboração própria a partir de dados da Rais.

Finalmente, para uma análise dos subsetores de defesa do ponto de vista de sua distribuição geográfica, é nítida a concentração no estado do Rio de Janeiro. Nos subsetores de defesa, manutenção de aeronaves, construção de embarcações e manutenção de embarcações há a predominância dos postos de trabalho nesse estado.

Contudo, em São Paulo há a predominância dos trabalhadores de fabricação de turbinas e fabricação de aeronaves. No Rio Grande do Sul predominam os trabalhadores de equipamentos bélicos pesados, armas e munições, enquanto no Paraná predominam os trabalhadores ligados ao subsetor de explosivos. 
Tabela 3 - Distribuição estadual nos setores ligados à economia da defesa (2013)

\begin{tabular}{|c|c|c|c|c|}
\hline $\begin{array}{l}\text { Unidade } \\
\text { federativa }\end{array}$ & Defesa & $\begin{array}{c}\text { Equipamento } \\
\text { bélico pesado, } \\
\text { armas e munição }\end{array}$ & Explosivos & $\begin{array}{c}\text { Manu- } \\
\text { tenção de } \\
\text { aeronaves }\end{array}$ \\
\hline 11 - Rondônia & 907 & 0 & 5 & 0 \\
\hline 12 - Acre & 49 & 0 & 0 & 0 \\
\hline 13 - Amazonas & 5.790 & 0 & 0 & 0 \\
\hline 14 - Roraima & 735 & 0 & 0 & 0 \\
\hline 15 - Pará & 5.779 & 0 & 184 & 32 \\
\hline 16 - Amapá & 174 & 0 & 0 & 0 \\
\hline 17 - Tocantins & 0 & 0 & 137 & 0 \\
\hline 21 - Maranhão & 910 & 0 & 5 & 15 \\
\hline 22 - Piauí & 36 & 0 & 0 & 8 \\
\hline 23 - Ceará & 1.827 & 0 & 40 & 0 \\
\hline $\begin{array}{l}24 \text { - Rio Grande } \\
\text { do Norte }\end{array}$ & 3.748 & 0 & 0 & 0 \\
\hline 25 - Paraíba & 147 & 0 & 0 & 0 \\
\hline 26 - Pernambuco & 5.168 & 0 & 85 & 0 \\
\hline 27 - Alagoas & 11 & 0 & 2 & 31 \\
\hline 28 - Sergipe & 94 & 0 & 0 & 0 \\
\hline 29 - Bahia & 2.878 & 0 & 115 & 2 \\
\hline 31 - Minas Gerais & 3.158 & 1.119 & 3.351 & 217 \\
\hline 32 - Espírito Santo & 385 & 0 & 7 & 18 \\
\hline $\begin{array}{l}33 \text { - Rio de } \\
\text { Janeiro }\end{array}$ & 56.319 & 76 & 1.300 & 2.599 \\
\hline 35 - São Paulo & 14.528 & 2.794 & 1.255 & 1.820 \\
\hline 41 - Paraná & 1.980 & 52 & 1.324 & 169 \\
\hline $\begin{array}{l}42 \text { - Santa } \\
\text { Catarina }\end{array}$ & 1.360 & 0 & 518 & 0 \\
\hline $\begin{array}{l}43 \text { - Rio Grande } \\
\text { do Sul }\end{array}$ & 4.556 & 2.818 & 140 & 1.303 \\
\hline $\begin{array}{l}50 \text { - Mato Grosso } \\
\text { do Sul }\end{array}$ & 2.425 & 0 & 0 & 86 \\
\hline 51 - Mato Grosso & 211 & 0 & 0 & 53 \\
\hline 52 - Goiás & 1.239 & 9 & 99 & 382 \\
\hline $\begin{array}{l}53 \text { - Distrito } \\
\text { Federal }\end{array}$ & 216.808 & 0 & 0 & 17 \\
\hline $\begin{array}{l}\text { Unidade } \\
\text { federativa }\end{array}$ & $\begin{array}{c}\text { Fabricação } \\
\text { de aeronaves }\end{array}$ & $\begin{array}{c}\text { Construção } \\
\text { de embarcações }\end{array}$ & $\begin{array}{c}\text { Manutenção } \\
\text { de embarcações }\end{array}$ & $\begin{array}{c}\text { Fabricação } \\
\text { de turbi- } \\
\text { nas }\end{array}$ \\
\hline 11 - Rondônia & 0 & 0 & 7 & 0 \\
\hline 12 - Acre & 0 & 0 & 0 & 0 \\
\hline 13 - Amazonas & 0 & 53 & 564 & 0 \\
\hline 14 - Roraima & 0 & 0 & 0 & 0 \\
\hline 15 - Pará & 0 & 27 & 99 & 0 \\
\hline 16 - Amapá & 0 & 3 & 16 & 0 \\
\hline
\end{tabular}

Continua... 
Conclusão.

\begin{tabular}{|c|c|c|c|c|}
\hline $\begin{array}{l}\text { Unidade } \\
\text { federativa }\end{array}$ & $\begin{array}{l}\text { Fabricação } \\
\text { de aeronaves }\end{array}$ & $\begin{array}{c}\text { Construçãa } \\
\text { de embarcações }\end{array}$ & $\begin{array}{c}\text { Manutenção } \\
\text { de embarcações }\end{array}$ & $\begin{array}{c}\text { Fabricação } \\
\text { de turbi- } \\
\text { nas }\end{array}$ \\
\hline 17 - Tocantins & 0 & 0 & 0 & 0 \\
\hline 21 - Maranhão & 0 & 6 & 40 & 0 \\
\hline 22 - Piauí & 0 & 0 & 0 & 0 \\
\hline 23 - Ceará & 0 & 16 & 9 & 0 \\
\hline $\begin{array}{l}24 \text { - Rio Grande } \\
\text { do Norte }\end{array}$ & 0 & 0 & 17 & 0 \\
\hline 25 - Paraíba & 0 & 0 & 0 & 0 \\
\hline 26 - Pernambuco & 3 & 1.706 & 18 & 0 \\
\hline 27 - Alagoas & 0 & 3 & 7 & 0 \\
\hline 28 - Sergipe & 0 & 2 & 3 & 0 \\
\hline 29 - Bahia & 72 & 9 & 669 & 0 \\
\hline 31 - Minas Gerais & 850 & 1 & 17 & 0 \\
\hline 32 - Espírito Santo & 0 & 33 & 191 & 0 \\
\hline $\begin{array}{l}33 \text { - Rio de } \\
\text { Janeiro }\end{array}$ & 83 & 4.502 & 7.095 & 42 \\
\hline 35 - São Paulo & 19.300 & 367 & 825 & 2.653 \\
\hline 41 - Paraná & 15 & 7 & 71 & 5 \\
\hline $\begin{array}{l}42 \text { - Santa } \\
\text { Catarina }\end{array}$ & 2 & 525 & 797 & 0 \\
\hline $\begin{array}{l}43 \text { - Rio Grande } \\
\text { do Sul }\end{array}$ & 27 & 668 & 71 & 0 \\
\hline $\begin{array}{l}50 \text { - Mato Grosso } \\
\text { do Sul }\end{array}$ & 0 & 0 & 10 & 0 \\
\hline 51 - Mato Grosso & 5 & 0 & 11 & 1 \\
\hline 52 - Goiás & 5 & 2 & 14 & 4 \\
\hline $\begin{array}{l}53 \text { - Distrito } \\
\text { Federal }\end{array}$ & 11 & 0 & 20 & 0 \\
\hline
\end{tabular}

Fonte: Elaboração própria a partir de dados da Rais.

Os dados demonstram um setor altamente concentrado demograficamente com salários demonstrando relativamente o baixo capital humano em uma função de produção com viés acentuado para o uso intensivo de mão de obra, em um cenário global de grande apelo tecnológico em equipamentos e sistemas de informação, bem como grande esforço no aperfeiçoamento das estratégias militares.

\section{Considerações Finais}

O tema da economia da defesa é recente na história econômica mundial e brasileira, sendo que os primeiros documentos publicados no Brasil, pelas autoridades governamentais citando a economia da defesa, datam dos primeiros anos do presente século. Além disso, há uma percepção de análise voltada para a indústria e a análise do orçamento público, destarte os diversos temas que tratam da economia da defesa. 
Este trabalho, buscando dirimir esse equívoco na literatura nacional, promoveu uma pesquisa integrada em economia da defesa, apresentando, a partir de uma perspectiva histórica, as potencialidades internas do Brasil para o desenvolvimento dos temas da economia da defesa bem como suas limitações.

$\mathrm{O}$ artigo explorou temas cruciais para o desenvolvimento da defesa nacional, como a revitalização da indústria e seu potencial de geração de emprego e renda, e o alinhamento político do país, que, por intermédio de suas forças econômicas, aspectos demográficos e disponibilidade de recursos naturais, possibilitou avanços na consolidação global do país.

Como resultado deste estudo é possível extrair que a indústria da defesa encontra dificuldades pela ausência de produção contínua na área, de modo que cada novo projeto demanda muito tempo para ser planejado e executado, fato que pode ser dirimido não apenas por inversões públicas, mas pela gestão racional dos recursos visando a competitividade dos sistemas, equipamentos e conceitos, garantindo a demanda perene em novos mercados, alinhando-se, por meio do soft power, ao posicionamento geopolítico do país.

Tratando-se do processo de alinhamento geopolítico, tem-se que as várias fases, desde o processo de redemocratização, iniciando com aproximação dos países do Cone Sul pelo Brasil, foram responsáveis pela projeção e consolidação global do Brasil. Contudo, ainda há muito para avançar, com destaque para o âmbito econômico, com transferência de tecnologia, produção bélica e acordos na área energética, principalmente com a África Ocidental, consolidando a capacidade de resiliência dos atores nacionais frente às vicissitudes do orçamento federal, bem como dos movimentos internacionais, por meio da produtividade, garantindo a perenidade dos níveis de escala e escopo.

Quanto à perspectiva da economia da defesa enquanto linha teórica, tem-se o desenvolvimento do tema intensificado após o fim da Guerra Fria, quando a corrida armamentista deu espaço a estudos referentes ao impacto no desenvolvimento econômico, indústria da defesa e questões estratégicas. Os métodos de pesquisa são diversos, com enfoque microeconômico ou macroeconômico, utilizando técnicas econométricas avanças ou métodos qualitativos. Embora o número de estudos ainda seja restrito, pode ser observada a sua ampliação constante. Os resultados encontrados até então são distintos.

Para o caso brasileiro, o estudo apontou que a produção de equipamentos militares nacionais teve inconstâncias. Vários foram os incentivos à indústria nacional, mas ainda há necessidade de investimentos tecnológicos, ampliação do perfil de pesquisa e desenvolvimento, bem como a promoção internacional das iniciativas, embebida na política de internacionalização erigida nas última duas décadas.

Cabe destacar, sobre os recursos aplicados na área, que se percebe uma estabilidade nos gastos - 1,5\% do PIB de 2004 a 2009. A tendência internacional é a re- 
dução nos gastos com defesa, porém os gastos brasileiros ainda são muito centrados em despesa com pessoal e pouco destinados a investimento e tecnologia, existindo, portanto, perenidade na alocação orçamentária, porém sem discussão sobre os impactos da função de produção da defesa na efetividade da PND e da END.

Por fim, quanto ao emprego e renda gerados pelo setor, os militares ativos das forças brasileiras somavam, em 2013, 331.222 trabalhadores. Quando contabilizados todos os setores pertencentes à indústria de defesa, tem-se 394.988 trabalhadores, aproximadamente $1 \%$ da força de trabalho formalizada do país. A distribuição geográfica dos setores ligados à economia da defesa denota grande concentração no Rio de Janeiro em termos gerais, porém São Paulo destaca-se na fabricação de turbinas e aeronaves, Rio Grande do Sul com equipamentos bélicos pesados, armas e munições e no Paraná há predomínio de trabalhadores ligados ao subsetor de explosivos.

A proposta de pesquisa integrada vai ao encontro do esforço para preencher uma grande lacuna da literatura nacional, ao galgar para a concepção de mecanismo que delineia o entendimento das necessidades do país quanto à defesa nacional, em especial quanto ao custo de oportunidade para a manutenção de forças armadas equilibradas, balanceadas e eficientes, frente à capacidade de colaborar para a efetivação do posicionamento geopolítico elencado nos objetivos nacionais, os quais são decididos em todo o sufrágio universal das eleições gerais, típico de um regime democrático. Por sua vez, o custo social de investir em defesa pode ser analisado com a exploração ampla dos temas ligados à economia da defesa, incentivando a criação do processo de tese, antítese e nova tese no meio acadêmico, empresarial e público no Brasil, com efetiva participação da sociedade civil e militar no bojo da proposta seminal intrínseca no Liuro Branco de Defesa Nacional.

\section{Referências}

ABU-BADER, S.; ABU-QARN, A.S. Government expenditures, military spending and economic growth: causality evidence from Egypt, Israel and Syria. Journal of Policy Modelling, v. 25, p. 567-583, 2003.

AIZENMAN, J.; GLICK, R. Despesas militares, ameaças e crescimento. Jornal do Comércio Internacional e Desenvolvimento Econômico, v. 15, n. 2, p. 129-155, 2006.

ALBALATE, D.; BEL, G.; ELIAS, F. Institutional determinants of military spending. Journal of Comparative Economics, v. 40, p. 279-290, 2012.

AMARANTE, J. C. A. A base industrial de defesa brasileira. Textos para Discussão - IPEA, n. 1758,2012

ARAGÃO, C. H. S.; SOBRAL, E. F. M.; MELO, S. R. S.; MELO, F. V. S. Impacto das despesas públicas por função no crescimento econômico brasileiro. Observatorio de la Economía 
Latinoamericana, n. 171, 2012. Disponível em: http://www.eumed.net/cursecon/ecolat/br/. Acesso em: 29 jan. 2020.

BRADDON, D. Regional impact of defense expenditure. In: HARTLEY, K.; SNADLER, T. (eds). Handbook of defense economics. V. 1. Amsterdã: North-Holland, 1995, p. 491-521.

BRASIL. Constituição da República Federativa do Brasil. Brasília: Centro Gráfico do Senado Federal, 1988, 292 p.

BRASIL. Ministério da Defesa. Decreto no 5.484, de 30 de junho de 2005. Aprova a Política de Defesa Nacional, e dá outras providências. Diário Oficial da União: seção 1, Brasília, DF, 01 de jul 2005. Disponível em: http://www.planalto.gov.br/ccivil_03/_Ato2004-2006/2005/ Decreto/D5484.htm. Acesso em: 1 out. 2012.

BRASIL. Política nacional de defesa. Estratégia Nacional de Defesa, p. 34, 2008. Disponível em: https://www.defesa.gov.br/arquivos/estado_e_defesa/END-PND_Optimized.pdf. Acesso em: 29 jan. 2020.

BRASIL. Liuro Branco de Defesa Nacional. Brasília: Ministério da Defesa, 2012, p. 50.

BRUMM, H. J. Military spending, government disarray and economic growth: a cross-country empirical analysis. Journal of Macroeconomics, v. 19, n. 4, p. 827-838, 1997.

CALDEIRA. J. História da riqueza no Brasil: cinco séculos de pessoas, costumes e governos. Rio de Janeiro: Estação Brasil, 2017, 624 p.

CENTER FOR STUDIES IN DEFENSE RESOURCES MANAGEMENT. The economic impact of Canadian defense expenditure. Kingston: The Royal Military College of Canada, 1983

CHANG, H.C.; HAUNG, B.N.; YANG, C.W. Military spending and economic growth across different groups: an dynamic panel Granger-causality approach. Economic Modelling, v. 28, p. 2416-2423, 2011.

CONCA, K. A industrialização militar do Brasil: o período pré-64. In: PROENÇA JÚNIOR, D. (Org.). Uma avaliação da indústria bélica brasileira: defesa, indústria e tecnologia. Rio de Janeiro: Universidade Federal do Rio de Janeiro, 1993, p. 173-195.

CRUZ JUNIOR, S. C. A segurança e defesa cibernética no Brasil e uma revisão das estratégias dos Estados Unidos, Rússia e Índia para o espaço virtual. Textos para Discussão - IPEA, n. 1850, 2013.

D`AGOSTINO, G.; DUNNE, J. P.; PIERONI, L. Optimal military spending in the U.S.: a time series analysis. Economic Modelling, v. 28, p. 1068-1077, 2011.

DAKURAH, A. H.; DAVIES, S. P.; SAMPATH, S. A. Defense spending and economic growth in developing countries, a causality analysis. Journal of Policy Modelling, v. 23, p. 651-658, 2001 .

DEPARTMENT OF DEFENSE - DOD. Defense economic impact modelling system annual forecasts. Washington, DC: Department of Defense, 1980. 
DRITSAKIS, N. Defense spending and economic growth: an empirical investigation for Greece and Turkey. Journal of Policy Modelling, v. 26, p. 249-264, 2004.

DUNNE, J. P. The defense industrial base. In: HARTLEY, K.; SNADLER, T. (eds). Handbook of defense economics. V. 1. Amsterdã: North-Holland, 1995, p. 399-430.

DUNNE, J.P.; SMITH, R.P.. The econometrics of military arms race. In: HARTLEY, K.; SNADLER, T. (eds). Handbook of defense economics. Amsterdam: North-Holland, 2007. v. 1, p. 913-940.

DUNNE, J.P.; SMITH, R.P. The economic consequence of reduced UK military expenditure. Cambridge Journal of Economics, v. 8, n. 3, p. 297-310, Sept. 1984.

FREDERIKSEN, P.C.; LACIVITA, C. J. Defense spending and economic growth: time series evidence on causality for the Philippines, 1956-1982. Journal of Philippine Development, v. 14, n. 2, p. 354-360, 1987.

HARTLEY, K. Defense economics: achievements and challenges. The Economics of Peace and Security Journal, v. 2, n.1, 2007.

HARTLEY, K.; SANDLER, T. Introduction. In: HARTLEY, K.; SNADLER, T. (eds). Handbook of defense economics. V. 1. Amsterdã: North-Holland, 1995, p. 1-11.

HITCH, C. J.; McKEAN, R. N. The economics of defense in the nuclear age. Cambridge, MA: Harvard University Press, 1960.

KOLLIAS, C; MANOLAS, G.; PALEOLOGOU, S. M. Defence expenditure and economic growth in the European Union, a causality analysis. Journal of Policy Modelling, v. 26, n. 5, p. 553-569, 2004.

LACIVITA, C. J.; FREDERIKSEN, P. C. Defense Spending and economic growt, an alternative approach to the causality role. Journal of Development Economics, v. 35, p. 117-126, 1991.

LANDAU, D. Is one of the "peace dividends" negative? Military expenditure and economic growth in the wealthy OCDE countries. The Quartely Review of Economics and Finance, v. 36, n. 2, p. 183-195, 1996.

LESSA, C. Indústria de defesa. In: PINTO, J. R. A.; ROCHA, A. J. R.; SILVA, R. D. P. (Org.). As forças armadas e o desenvolvimento científico e tecnológico do país. V. 3. Brasília: Ministério da Defesa - Secretaria de Estudos e Cooperação, 2004, p. 13-22.

LIPOW, J.; ANTINOLI, C. M. External security threats, defense expenditures, and the economic growth of less-developed countries. Journal of Policy Modelling, v. 17, n. 6, p. 579-595, 1995.

MAIZELS, A.; NISSANKE, M. K. The determinants of military expenditures in developing countries. World Development, v. 14, n. 9, p. 1125-1140, 1986.

MATOS, P. O. Orçamento e Defesa nacional: uma análise da participação do setor Defesa no orçamento federal de 2000 a 2009. In: III SEMINÁRIO DE ESTUDOS: PODER AEROESPA- 
CIAL E ESTUDOS DE DEFESA, 2010, Rio de Janeiro. Anais eletrônicos [...]. Rio de Janeiro: Universidade da Força Aérea, 2010.

McGUIRE, M. Defense economics and international strategy. In: HARTLEY, K.; SNADLER, T. (eds). Handbook of defense economics. V. 1. Amsterdã: North-Holland, 1995, p. 14-43.

MIYAMOTO, S. Política externa, defesa e armamentos. In: III SEMINÁRIO NACIONAL DE CIÊNCIA POLÍTICA, 2010, Porto Alegre. Anais eletrônicos [...]. Porto Alegre: Universidade Federal do Rio Grande do Sul, 2010.

MORAES, R. F. Ascensão e queda das exportações brasileiras de equipamentos brasileiros. Boletim de Economia e Política Internacional - IPEA, n.3, p. 59-70, 2010.

NASCIMENTO, D. M. A política de Defesa nacional para a Amazônia e suas consequências ao programa Calha Norte. Humanitas - UFPA, v. 22, p. 27-46, 2006.

PIERONI, L. Does defence expenditure affect private consumption? Evidence from the United States. Economic Modelling, v. 26, p. 1300-1309, 2009.

PIERONI, L.; D`AGOSTINO, G.; LORUSSO, M. Can we declare military Keynesian dead ? Journal of Policy Modelling, v. 30, p. 675-691, 2008.

RAIS: relatório anual de informações sociais. [2020]. Disponível em: http://bi.mte.gov.br/ bgcaged/login.php. Acesso em: 30 jan. 2018.

REISS, D. G. Defense expenditures in Brazil: a qualitative analysis of the federal budget for the period from 2001 to 2007. Munich Personal Repec Archive (MPRA) Paper, n. 47373, 2008.

RICHARDSON, L. F. Arms and insecurity: a mathematical study of the causes and origins of war. Pittsburgh, PA: Homewodd, 1960.

ROCHA, F., GIUBERTI, A. C. Composição do gasto público e crescimento econômico: um estudo em painel para os Estados brasileiros. In: ENCONTRO NACIONAL DA ANPEC, 33. 2005, Natal. Anais eletrônicos [...]. Natal: ANPEC, 2005. Disponível em: http://www.anpec. org.br/encontro2005/artigos/A05A049.pdf. Acesso em: 30 jan. 2020.

SCHELING, T. C. The strategy of conflict. Cambridge, MA: Harvard University Press, 1960.

SCHMIDT, F. H. Desafios e oportunidades para uma indústria espacial emergente: o caso do Brasil. Textos para Discussão - IPEA, n. 1667, 2011.

SCHMIDT, F. H.; ASSIS, L. R. S. A dinâmica recente do setor de defesa no Brasil: análise das características e do envolvimento das firmas contratadas. Textos para Discussão - IPEA, $\mathrm{n}$. 1878, p. 55, 2013.

SCHOFIELD, S. Defense technology, industrial structure and arms conversion. In: COOPEY, R.; UTTLEY, M.; SPORARDI, G. (eds.). Defense science and technology: adjusting to change. Amsterdã: Harwood Academic Publishers, 1993. 
SHIEH, J. Y.; LAI, C. C.; CHANG, W. Y. The impact of military burden on long-run growth and welfare: short communication. Journal of Development Economics, v. 68, p. 443-454, 2002.

SILVA, A. M. M.; OLIVEIRA, G. Z.; BRITES, P. V. P. A política externa brasileira para a África Ocidental e o panorama securitário do Atlântico Sul a partir do governo Lula. In: IV ENCONTRO NACIONAL DA ASSOCIAÇÃO BRASILEIRA DE RELAÇÕES INTERNACIONAIS: MULTILATERALISMO, PLURILATERALISMO E A CONSTRUÇÃO DE UMA ORDEM MUNDIAL, 2013, Belo Horizonte. Anais eletrônicos [...]. Belo Horizonte: ABRI, 2013.

WALKER, W.; GRAHAM, M.; HARBOR, B. From components to integrated systems: technological diversity and interactions between military and civilians sectors. In: GUMMETT, P.; REPPY, J. (eds) The relation between military and civilians technologies. Dordrecht, NL: Kluwer Academic Publishers, 1988, p. 17-37.

WU, S. Y.; TANG, J. H.; LIN, E. S. The impact of government expenditure on economic growth: how sensitive to the level of development? Journal of Policy Modelling, v. 32, p. 804$817,2010$.

Recebido em: 24/10/2017. Aceito em: 18/09/2018. 